\title{
Coleta seletiva de lixo: elaboração do jogo lixo amigo
}

\section{Selective waste collection: elaboration of "lixo amigo" game}

\author{
${ }^{1}$ Patricia Soares Rocha Alves \\ ${ }^{1}$ Ana Paula Gomes de Souza \\ ${ }^{2}$ Denise Celeste Godoy de Andrade Rodrigues denise.cgar@gmail.com
}

\section{RESUMO}

O objetivo deste trabalho é ensinar para as crianças do ensino fundamental, através do jogo Lixo Amigo, como é feita a coleta seletiva de lixo, inserindo nesta nova geração uma tentativa de mudança de hábito em relação ao meio ambiente. O processo de criação e desenvolvimento do produto foi realizado a partir da metodologia de design, que é feita através de cinco tópicos: identificação do problema, pesquisa de geração de alternativas, partido adotado, teste de aplicabilidade e produto final. Após a identificação do problema foi feita uma pesquisa de gerações de alternativas. Nela aconteceram vários testes de materiais e funções, chegando-se ao partido adotado que foi feito através do teste de aplicabilidade. Para confirmação das faixas etárias propostas e validação da eficiência do projeto, aplicou-se o jogo em dez turmas do ensino fundamental de uma escola particular e outra municipal, totalizando 251 crianças. O resultado obtido foi satisfatório para todas as faixas etárias e ficou comprovado, através dos questionários respondidos pelas professoras, a eficácia da dinâmica e aplicação do jogo em relação a coleta seletiva de lixo.

Palavras-chave: Coleta seletiva de lixo, Jogo, Meio ambiente, Ensino Fundamental.

\begin{abstract}
The objective of this work is to teach elementary school children, through play Trash Friend, how is the garbage collection, this new generation entering an attempted change of habit in relation to the environment. The process of creation and development of the product was carried out from the design methodology, which is done through five topics: problem identification, research, generation of alternatives, the party adopted, applicability and test the final product. After identifying the problem, research was done to generations of alternatives. It happened several tests of materials and functions, came to the party adopted: the applicability test. For confirmation of the age groups and validation of the proposed project efficiency, the game was applied on ten classes of elementary schools private and municipal, totaling 251 children. The result was satisfactory for all age groups and has been proven, through questionnaires answered by teachers, the effectiveness of the dynamics and learning about the garbage collection.
\end{abstract}

Keywords: Selective Collection of garbage, Game, environment, elementary school.

1 Centro Universitário de Volta Redonda - UniFOA.

2 Centro Universitário de Volta Redonda - UniFOA, Universidade do Estado do Rio de Janeiro - UERJ. 


\section{INTRODUÇÃO}

A Revolução Industrial, juntamente com o crescimento populacional e os avanços tecnológicos originaram transformações na natureza com consequências até os dias atuais. $\mathrm{O}$ aumento nas escalas de produção, exploração desordenada de recursos naturais e o incentivo ao consumo desenfreado ocasionaram problemas ambientais como o aumento na geração e descarte de resíduos (BARBIERI, 2007).

A quantidade de lixo produzida diariamente no Brasil corresponde entre 180 a 250 mil toneladas de resíduos sólidos urbanos (IBGE, 2010), sendo que alguns materiais como o papel, o plástico, o vidro e o metal são muito importantes para a redução da exploração ambiental, já que estes, na atualidade, são os principais componentes dos produtos mais consumidos (SOBRAL, 2012, p. 2).

Grande parte desses resíduos são gerenciados de maneira inadequada e são destinados a disposição final. Muitos são passíveis de reaproveitamento e/ou reciclagem (BRASIL, 2010). Desta maneira, o conjunto de informações e conscientização tornam-se importantes para melhor aproveitamento dos resíduos e os processos de reciclagem e coleta seletiva constituem uma intervenção necessária para direcionamento dos resíduos que foram gerados e que necessitam de uma destinação correta (ZANETI, 1997).

A Educação Ambiental vem sendo inserida no meio social com o objetivo de propiciar uma compreensão crítica e global do ambiente, desenvolvendo no sujeito valores e atitudes para que o mesmo tome um novo posicionamento mais consciente e participativo a respeito das questões ambientais (MOTA JUNIOR, 2009).

Reigota (2009, p.08) enfatiza que a educação ambiental deve "capacitar os indivíduos ao pleno exercício da cidadania, permitindo a formação de uma base conceitual suficientemente diversificada técnica e culturalmente, de modo a permitir que sejam superados os obstáculos à utilização sustentável do meio”. Portanto, deve-se buscar alternativas que promovam uma contínua reflexão acerca do meio ambiente, como por exemplo, atividades e projetos que levem nossas crianças a brincarem com consciência, através do contato com práticas pedagógicas que façam com que elas tenham contato com a realidade.

Com o objetivo de desenvolver um novo olhar para a educação, a ecopedagogia surge como proposta pedagógica que promove a aprendizagem das coisas a partir da vida cotidiana, valorizando a vida e promovendo o equilíbrio entre os seres vivos e não vivos (GUTIERREZ, 1994; GADOTTI, 1998; LIBÂNEO, 2005).

A sustentabilidade como educação visa à conscientização do homem de que sua vida e a vida dos demais seres vivos estão intimamente ligadas, inserindo-os no mundo com uma visão global e a partir de seu cotidiano, buscar sentido em cada momento (GADOTTI, 1998).

Para desenvolver e auxiliar essa visão global no contexto educacional, destaca-se o papel dos jogos, que apresentam entre suas principais vantagens o fato de tornarem os estudantes participantes mais ativos e não apenas observadores, resolvendo problemas, tomando decisões e reagindo aos resultados dos mesmos (KISHIMOTO, 1993).

A aquisição de conhecimento pode ser facilitada quando toma a forma de atividade lúdica, pois os alunos ficam entusiasmados ao receberem a proposta de aprender de uma forma mais interativa e divertida. Nesse contexto, o jogo não é o fim visado, mas o eixo que conduz a um conteúdo didático determinado. Ele resulta de um empréstimo da ação lúdica para servir à aquisição de informações (KISHIMOTO, 1993).

Como é citado por Piaget (1978, p.47) “O indivíduo, seja criança ou adulto, revive no jogo a maioria das atividades pelas quais passou a espécie, em sua metódica evolução, durante milênios”. O jogo representa para a criança o papel que o trabalho representa para o adulto. 
Objetivando-se contribuir para a educação ambiental nas escolas, utilizamos a temática da separação correta do lixo para a confecção de um jogo educativo para ser utilizado como material paradidático em sala de aula.

\section{PERCURSO METODOLÓGICO}

A pesquisa utilizada neste trabalho foi descritiva, com abordagem qualitativa, e feita em duas escolas de Volta Redonda, uma municipal e outra particular. O projeto foi aprovado pelo Comitê de Ética em Pesquisa Envolvendo Seres Humanos, sob o número CAE 08246512.8.0000.5237.

A coleta de dados foi realizada por meio da aplicação de um questionário semi-estruturado aos professores das turmas do primeiro ao quinto ano do ensino fundamental das escolas definidas: Escola Municipal Miguel Couto Filho, no Jardim Normândia, e o Colégio Interativo, na Vila Santa Cecília, ambos em Volta Redonda. Nesses colégios, mesmo havendo estrutura propícia para se fazer coleta seletiva de lixo, nem sempre as crianças a utilizavam de maneira correta.

O jogo foi aplicado em 10 turmas, totalizando 261 crianças e 10 professores participantes.

\section{DESENVOLVIMENTO DO JOGO}

Para o desenvolvimento de criação do jogo utilizou-se a metodologia de design, segundo MUNARI (1997, p. 22). O ato de planejar, organizar os símbolos, as palavras, os desenhos e as imagens com o intuito de comunicar são reconhecidos como design gráfico. O design gráfico é uma especialidade da área do design que abrange uma gama de produções que vai desde a criação de uma marca, aplicação de cores e tipografias em peças gráficas, diagramação de jornais e revistas até aplicabilidade e facilidade em jogos e outros produtos.

O objetivo pensado para o jogo foi que a turma toda jogasse ao mesmo tempo e que todos os alunos estivessem envolvidos para que não houvesse dispersão por parte de algumas crianças. Para a elaboração do jogo foram feitas várias pesquisas de gerações de alternativas com tipos de materiais diferentes, análise de situações de jogo e tipos de ilustrações.

Para a trilha do jogo, após várias propostas, ficou definido o layout voltado para o meio ambiente e com as casas numeradas para facilitar a contagem (Figura 1), confeccionada em lona com impressão offset em policromia, com 2,5 por $1 \mathrm{~m}$.

Figura 1 - Layout do modelo voltado para o meio ambiente e casas numeradas

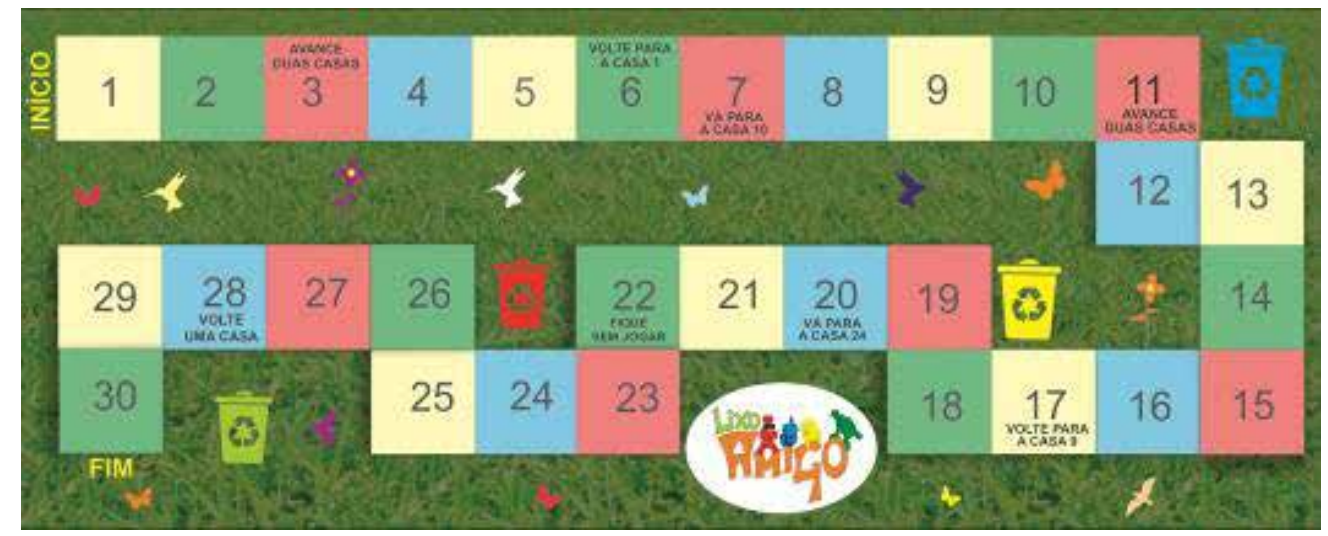

Fonte: dos autores. 
No lugar do dado do jogo, optou-se por um alvo (Figura 2) com tamanho 60 por $60 \mathrm{~cm}$, confeccionado em PVC 2mm. Como forma de selecionar o número de casas na jogada, utilizou-se uma bola de meia preta.

Figura 2 - Layout do modelo do alvo.

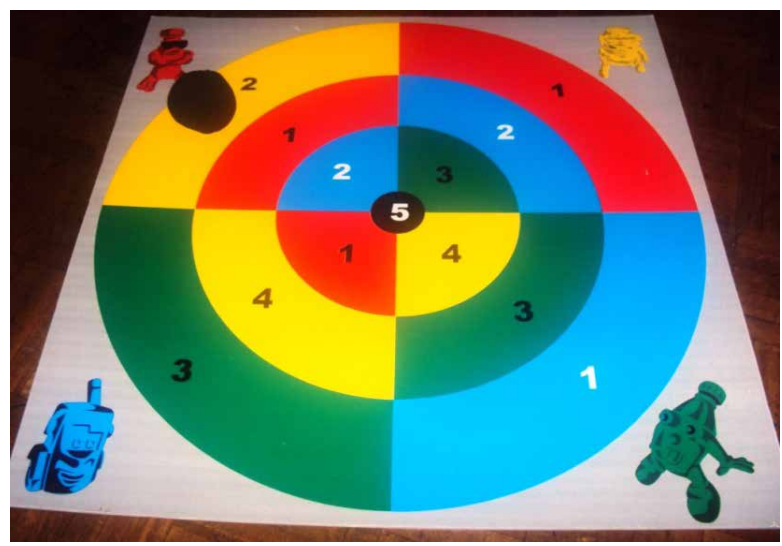

Fonte: dos autores.

Os peões do jogo foram confecionados em resina e coloridos com tinta collor Jet spray como mostrado na Figura 3.

Figura 3 - Peões do jogo em resina - da esquerda para a direita, Garrafa PET, Caixinha de Leite, Latinha de refrigerante e garrafa de vidro.

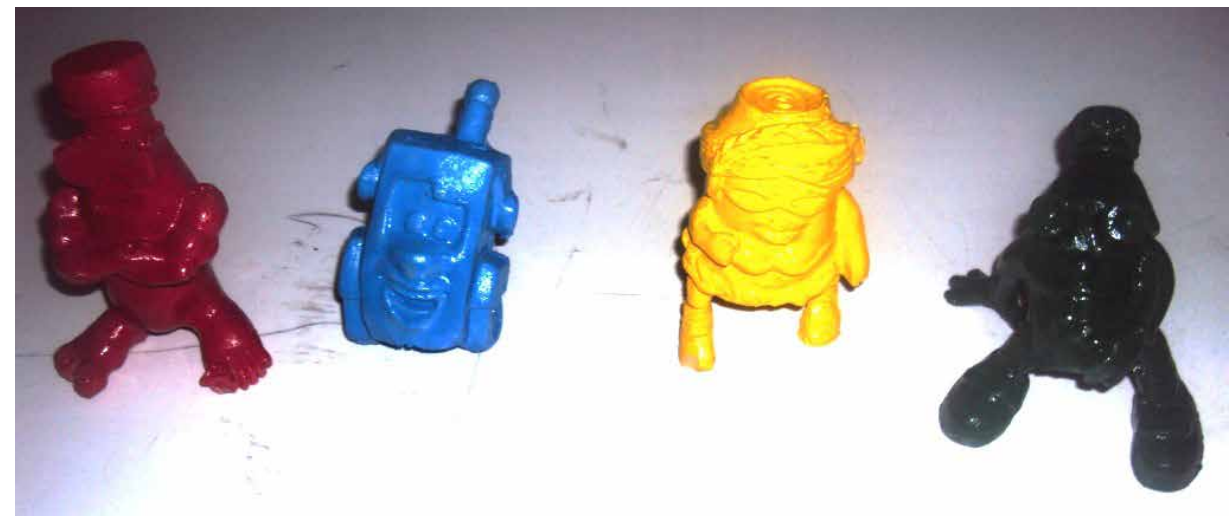

Fonte: dos autores.

Ao todo o jogo tem 56 cartas: 36 RECICLADAS, 10 NÃO RECICLADAS e 10 de ARTESANATO.

As RECICLADAS, exemplificadas na Figura 4, foram divididas em cores representando os tipos de lixo que se pode reciclar, contendo as informações mais importantes do jogo, quantas casas avançar e com o principal objetivo proposto: o de se jogar o lixo no lixo, de forma correta. 
Figura 4 - Layout de 2 modelos das 39 cartas referentes a cada tipo de lixo

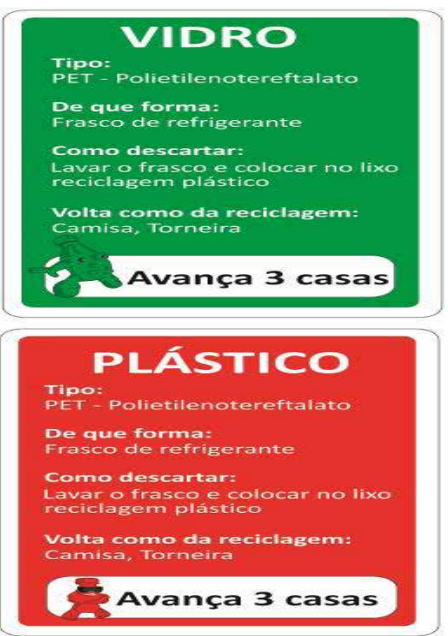

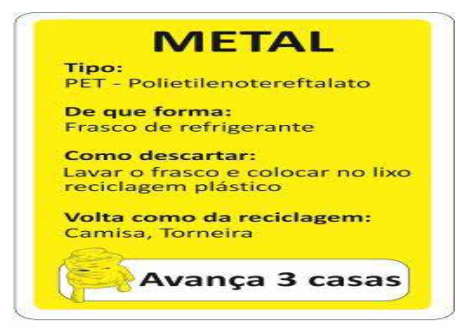

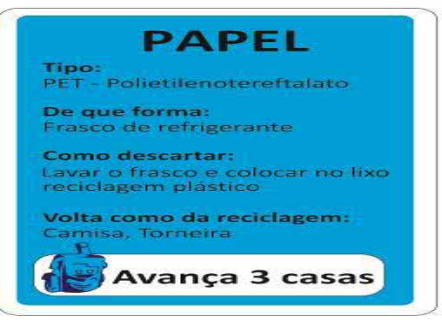

Fonte: dos autores.

As cartas com a inscrição NÃO RECICLADAS fornecem informações dizendo por que aquele material não é reciclável, onde descartá-lo e quantas casas o peão deve voltar.

Na Figura 5 estão as cartas ARTESANATO, que serão escolhidas pelo grupo vencedor para que toda a turma monte o brinquedo reciclado que consta nelas.

Figura 5 - Layout do conteúdo de 3 cartas artesanato - cartas prêmio
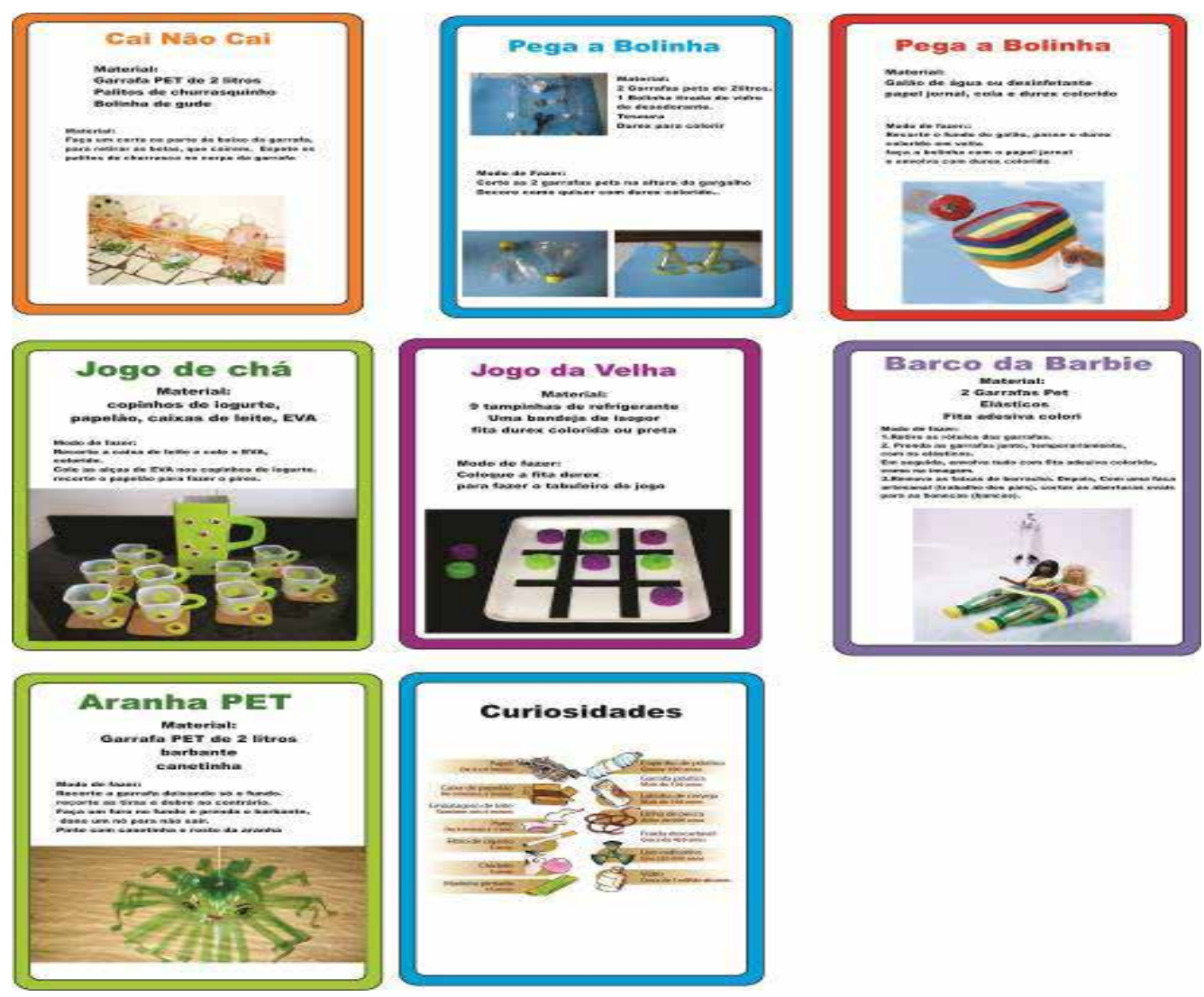

Fonte: dos autores. 


\section{1 Teste de Aplicabilidade do Jogo}

A turma foi dividida em quatro grupos, um para cada cor correspondente a um tipo de lixo: amarelo (metal), vermelho (plástico), azul (papel) e verde (vidro) (Figura 7). As crianças vestiram, sobre o uniforme, abadás com as respectivas cores de cada grupo.

Cada grupo recebeu um peão referente ao tipo de lixo do seu grupo: papel (caixa de leite), vidro (garrafa de refrigerante), plástico (garrafa PET), alumínio (latinha de refrigerante). Para determinar quantas casas cada grupo andou foi lançada a bola de meia no alvo que estava no chão.

Após andar com o peão, a criança retirou uma carta, RECICLADA ou NÃO RECICLADA, para saber se iria avançar ou voltar casas com o peão.

Figura 7 - Layout dos abadás que serão vestidos pelos alunos da classe.

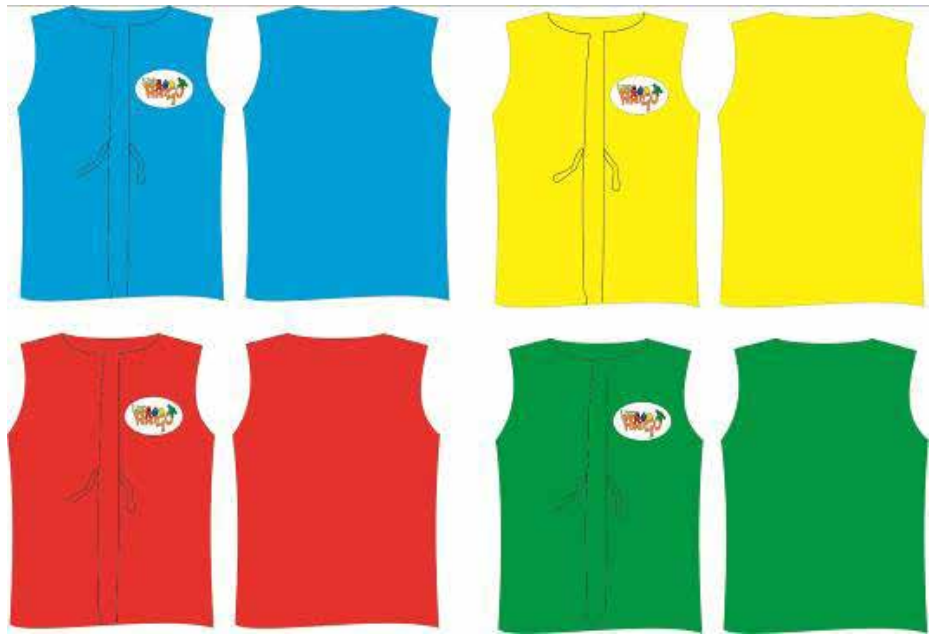

Fonte: dos autores.

O grupo vencedor escolheu ao final a carta ARTESANATO e a turma trouxe o material necessário na aula seguinte para confeccionar o produto/artesanato.

\section{RESULTADOS E DISCUSSÃO}

O questionário, respondido pelo professor de cada turma, inicia com a pergunta sobre a faixa etária adequada ao jogo. Neste caso, $100 \%$ dos entrevistados afirmaram que sim, o jogo está adequado para a faixa etária da turma de cada um. As faixas etárias aplicadas foram de 5 a 11 anos, referentes ao ensino fundamental $\mathrm{I}$ do $1^{\circ}$ ao $5^{\circ}$ ano.

Com relação às regras do jogo, apenas $10 \%$ consideraram que as crianças não absorveram direito as regras. Estes $10 \%$ são relativos a uma turma de $1^{\circ}$ ano da escola Municipal Miguel Couto. Segundo relato da professora, no começo do jogo elas não estavam conseguindo entender as regras, mas na medida em que o jogo foi dando seguimento ela relata que as regras foram ficando mais claras.

Isso pode ter ocorrido devido a faixa etária da turma ser de 5 a 6 anos. Como sugestão para que isso não ocorra, sugeriu colocar imagens nas cartas para ficar mais atrativo para essa faixa etária, contribuindo assim para que as crianças compreendam mais as regras logo de início e não fiquem dispersas. 
Os jogos educativos, além de oferecer desafios, possuem como objetivo agregar conhecimento educacional aos jogadores, ensinando algo (GULARTE, 2010). Portanto os jogos educativos podem, casualmente, proporcionar aquisição de conhecimento à medida que o jogador vai avançando no jogo. Acredita-se que foi isso que aconteceu, no decorrer da atividade as crianças foram entendendo mais a dinâmica do jogo.

Com relação ao entendimento sobre coleta seletiva por parte das crianças após o jogo, na opinião das professoras, $70 \%$ conseguiram saber mais como é esse procedimento.

Gramigna (2007) afirma que o jogo de conteúdo tem por objetivos fixar conteúdos e reforçar conceitos e referenciais teóricos. O Lixo Amigo, proposta do presente estudo, tem por objetivo, assim como o jogo de conteúdo, fixar conteúdos, através das cartas, e reforçar conceitos e referenciais teóricos sobre o tema coleta seletiva de lixo.

Com relação a agradar mais a meninos ou meninas, o jogo atraiu 90\% de ambos os gêneros, igualmente. Desses dez por cento relatados representam uma turma de 15 meninos e 11 meninas na faixa etária de 8 a 10 anos. Por serem maioria, os meninos ficaram mais empolgados que as meninas. Em relação à percepção, como educador, sobre a dinâmica do jogo, $60 \%$ classificaram como bom e $40 \%$ como muito bom.

Podemos observar segundo relato das professoras que o jogo atingiu o seu objetivo que era chamar a atenção das crianças para a importância da coleta seletiva para o meio ambiente, segundo relato do depoente 1.

... é um assunto real com o qual as crianças convivem diariamente: coleta seletiva, consciência ambiental, reciclagem, enfim todos estão presentes no nosso universo e dos alunos. Logo o jogo traz uma reflexão importante sobre atualidade e reforça a importância de todos esses conceitos de maneira responsável e criativa (Depoente 1).

O relato da depoente 5 reforça o lado lúdico dos jogos:

O jogo é uma maneira inteligente e divertida de trabalhar os conteúdos com nossas crianças. O jogo do lixo foi muito curtido pelos alunos e eles puderam aprender brincando sobre um assunto tão importante e atual: preservação do meio ambiente (Depoente 5).

Segundo Kanaane e Abussamra (2008) antes de constituir-se em atividade lúdica, o jogo é um instrumento muito importante nos processos de educação em geral. Por meio dele, as pessoas exercitam habilidades necessárias para seu desenvolvimento integral, assim como a autodisciplina, sociabilidade, afetividade, valores morais, espírito de equipe, bom senso, criatividade, espontaneidade e iniciativa.

Segundo Brown (1994), os jogos cooperativos possuem diversas características libertadoras, e, dentre elas, destacamos a libertação da agressão, que pode ser alcançada dando-se ênfase à participação e à autoestima de cada pessoa; criando-se jogos em que cada participante estabeleça seu próprio ritmo; adaptando-se jogos conhecidos, diminuindo a importância do resultado final e eliminando o contato físico do tipo destrutivo.

No Jogo Lixo Amigo observou-se que algumas crianças não estavam preocupadas com o final do jogo mas sim com o ato de ter contato com as peças do jogo que, segundo eles, eram muito atrativas. Isso ocorreu pelo fato das crianças pedirem para que ao final do jogo todos ganhassem a carta artesanato, podendo assim o grupo inteiro confeccionar os brinquedos com material reciclável.

"Uma característica essencial do jogo cooperativo é o envolvimento do grupo em um objetivo comum e a partir desse envolvimento todos os participantes passam a unir forças para que o objetivo seja alcançado" (MARTINS, 2005, p. 32). Corroborando com o autor, de acordo com relato das professoras a turma toda se uniu em prol de retirar a carta artesanato. 
O professor age como mediador, auxiliando os participantes a compreender e seguir as regras, a entender o objetivo do jogo, sendo sua ação imprescindível antes, durante e após a partida do jogo. Acredita-se que para o entendimento das regras para as crianças das faixas etárias de 5 à 6 anos a ação do professor foi de extrema importância para o jogo. No momento da leitura de uma carta ou outra que o aluno possa ter achado difícil não vemos problema algum na intervenção do professor, uma vez que através dela os alunos poderão aprender o conteúdo.

Observou-se que a dinâmica da atividade em relação a uma escola ser privada e a outra pública, em nada alterou a aplicabilidade do jogo, pois possuíam estrutura adequada para realização do jogo.

Na escola pública, consideraram que o jogo demorou muito para acabar. Isso pode ter ocorrido por não terem embaralhado direito as cartas e também pelo número grande de alunos. Já na escola privada a avaliação de todas as professoras foi muito boa. Isso pode ter ocorrido pelo fato das turmas serem menores.

Após o teste de aplicabilidade do produto foram realizadas algumas modificações no jogo:

A matéria-prima utilizada para a confecção dos peões foi alterada de resina para silicone colorido e emborrachado, que não quebra e quica no chão feito uma bolinha, sem perigo de quebrar ou de ferir quem está a volta. A meia foi substituída por saco de tecido com areia dentro e o alvo de PVC por lona 3M, no mesmo tamanho $(60 \mathrm{~cm}$ por $60 \mathrm{~cm})$ em impressão de policromia. Apenas por questões de durabilidade, o material de confecção das cartas foi substituído por PVC 0,5mm, que é mais resistente. Houve uma alteração na regra do jogo: todos chegam a reta final e tem direito de retirar a carta artesanato, não tendo assim um prêmio somente para quem chega primeiro. Ao final, todos saem vencedores.

A versão final detalhada do jogo encontra-se disponível em: < $\underline{\text { http://web.unifoa.edu.br/portal_ensino/ }}$ mestrado/mecsma/arquivos/2013/pd15.pdf>.

\section{CONCLUSÕES}

O referencial teórico desse trabalho aponta que a vivência de situações cooperativas pode contribuir para que os alunos aprendam a se relacionar de forma construtiva nos jogos, na escola e na vida social.

Como a função da escola é contribuir na formação integral dos alunos, acredita-se que os jogos semi- cooperativos possuem um potencial para contribuir nesta formação, especialmente em relação à dimensão atitudinal e meio social. Quando se joga cooperativamente é possível que os alunos envolvidos se entreguem plenamente ao jogo, respeitando e incluindo a si mesmos e aos outros. Pode-se perceber que nos jogos semi-cooperativos, a competição e a cooperação andam juntas.

De acordo com os dados levantados pelo questionário , pode-se concluir que o jogo funciona para todas as faixas etárias propostas e que as regras estão claras, o design é atrativo, despertando interesse em absorver o conteúdo sobre a coleta seletiva. 


\section{REFERÊNCIAS}

BARBIERI, J. Gestão Ambiental Empresarial: Conceitos, Modelos e Instrumentos. 2. ed. São Paulo: Saraiva, 2007.

BRASIL. Lei $\mathrm{n}^{\circ}$ 12.305, de 02 de agosto de 2010. Institui a Política Nacional de Resíduos Sólidos. Diário Oficial de União. Disponível em: <http://www.planalto.gov.br/ccivil_03/_ato2007-2010/2010/lei/112305.htm>. Acesso em: 26 set. 2015.

BROWN, G. Jogos cooperativos: teoria e prática. 2. ed. São Leopoldo: Sinodal, 1994.

GADOTTI, M. Ecopedagogia e Educação para a Sustentabilidade. Instituto Paulo Freire - Universidade de São Paulo, 1998. Disponível em: < http://www.biologia.ufrj.br/ereb-se/artigos/ecopedagogia_e_educacao.pdf $>$. Acesso em: 09 nov. 2015.

GRAMIGNA, M. R. Jogos de Empresa. 2a. ed. São Paulo: Pearson Prentice Hall, 2007. 180 p.

GULARTE, D. Jogos eletrônicos: 50 anos de interação e diversão. Teresópolis: Novas Ideias, 2010. 190p.

GUTIERREZ, F. Pedagogia para el Desarrollo Sostenible. Heredia, CostaRica, Editorialpec, 1994.

IBGE. Instituto Brasileiro de Geografia e Estatística. Pesquisa Nacional de Saneamento Básico, PNSB -2008. Rio de Janeiro: IBGE; 2010.

KANAANE, R.; ABUSSAMRA, J. Jogos em treinamento e desenvolvimento do potencial humano. Integração, n. 52, p. 83-93, 2008.

KISHIMOTO , T. M. O Jogo e a Educação Infantil. São Paulo : Pioneira, 1994.

LIBÂNEO, J. C. As teorias pedagógicas modernas revisitadas pelo debate contemporâneo na educação. Educação na era do conhecimento em rede e transdisciplinaridade, v. 3, p. 19-62, 2005.

MARTINS, R.G. Jogos Cooperativos na escola: a concepção de professores de educação física. Mestrado em psicologia da educação. PUC-SP, 2005.

MOTA JUNIOR, V. D. Educação Ambiental, política, cidadania e consumo. Interacções, Santarém, n.11, p. 214229, 2009. Disponível em: <http://nonio.eses.pt/interaccoes/artigos/K11\%281\%29.pdf> Acesso em: 10 dez. 2015.

MUNARI, B. Design e comunicação visual: Contribuição para uma metodologia didática; tradução Daniel Santana. São Paulo: Martins Fontes, 1997.

PIAGET, J. A Formação do Símbolo na Criança: imitação, jogo e sonho. Rio de Janeiro: Zanar, 1978.

; INHELDER, B. A psicologia da criança. Rio de Janeiro: Bertrand Brasil S.A, 1993.

REIGOTA, M. O que é educação ambiental. 2. ed. São Paulo: Brasiliense, 2009.

SOBRAL, C. R. S. Educação ambiental e resíduos sólidos: possibilidades para a construção de um pensamento crítico. Departamento de Ciências Naturais (DCNAT), 2012.

ZANETI, I. Além do lixo: reclicar: um processo de Trans Form Ação. Brasília: Terra Una, 1997. 133p. 